\title{
Detección de Amastigotes de Leishmania spp por frotis de Sangre Periférica en un adulto en Asunción, Paraguay. Reporte de caso
}

DOI: $10.46981 /$ sfjhv2n1-010

Received in: November 1st, 2020

Accepted in: December 30th, 2020

María José Tintel Astigarraga

Centro para el Desarrollo de la Investigación Científica (CEDIC)

Doctora en Ciencias Veterinaria 2014 (UNA). Especialista en Diagnóstico Anatomohistopatológico

Veterinario. 2018 (UNNE). Cursando doctorado en Ciencias de la Salud, Fundación Oswaldo Cruz (Fiocruz). Investigadora asociada del Centro para el desarrollo de la Investigación Científica (CEDIC).

E-mail: tintelvet@gmail.com

\section{RESUMEN}

Las leishmaniasis son enfermedades de transmisión vectorial e integran el grupo de las enfermedades infecciosas desatendidas, presentan una amplia distribución global y la mayoría de los casos ocurren en África, Asia y las Américas.

Este trabajo describe la detección de Amastigotes de Leishmania spp por frotis de Sangre Periférica en un adulto en Asunción- Paraguay. Tal abordaje resalta la posibilidad de diagnosticar la enfermedad en fase aguda, incluso antes de titulación de anticuerpos por un método sencillo y menos invasivo

Key words: leishmaniosis, parasite, vector, zoonosis.

\section{OBJETIVO ESPECÍFICO}

Determinar presencia de Amastigotes de Leishmania spp por medio de sangre periférica en un hombre con sintomatología inespecífica

\section{MARCO TEÓRICO DE REFERENCIA}

Las Leishmaniosis son un conjunto de enfermedades infecciosas, parasitarias, antropozoonóticas causadas por protozoarios flagelados del género Leishmania que cuenta con más de 20 especies diferentes, se conocen más de 90 especies de flebotominos transmisores de Leishmania. La OMS estima que cada año se producen entre 700.000 y un millón de nuevos casos y entre 26.000 y 65.000 defunciones. Solo una pequeña parte de las personas infectadas por Leishmania acaban padeciendo la enfermedad (OPS, 2019)

Los parásitos del género Leishmania cambian en forma intercalada hospedadores vertebrados e insectos de la subfamilia Phlebotominae, los cuales se alimentan de la sangre de los vertebrados, actuando como vectores biológicos de la enfermedad. En los vertebrados se desarrollan las formas amastigotes redondeadas pequeñas, sin flagelo externo, dentro de los macrófagos, en donde se 
multiplican por división binaria. Al picar el flebótomo a un animal vertebrado infectado, el insecto ingiere juntamente con la sangre y la linfa, macrófagos parasitados. En el tubo digestivo de los vectores se desarrollan, después de pocos días, las formas flageladas denominadas promastigotes, las cuales son infectivas para los vertebrados y que penetran en la piel de un nuevo hospedador no infectado (el hombre u otro animal susceptible) mediante una nueva picada del vector. En el lugar de la picadura, las formas promastigotes introducidas son fagocitadas por los macrófagos, en cuyo interior evolucionan a formas amastigotes que se dividen rápidamente. Dentro de esta célula, cuando los macrófagos están densamente parasitados se rompen, dejando en libertad a los amastigotes que son fagocitados por otros macrófagos, diseminándose de esta forma los parásitos en el nuevo hospedador, cerrando de esta manera el ciclo biológico (MSPBS, 2018)

En América, podemos hablar de dos tipos de leishmaniasis: leishmaniasis visceral americana (LVA) y leishmaniasis tegumentaria americana (LTA). En Paraguay, las zonas endémicas de la LTA, se ubican en el norte, centro y este de la Región Oriental. (MSPBS, 2018)

\section{METODOLOGÍA}

Toma de muestras de sangre por venopunción cefálica para análisis hematológicos y una gota de sangre digital para el extendido de frotis sanguíneo periférico.

Estudios por imágenes; ecografía y tomografía abdominal.

\section{RESULTADOS}

Hombre de 32 años, veterinario de pequeños y grandes animales con sintomatología diversa como fiebre, malestar general y valores hematológicos inespecíficos como leucopenia (3490/ mm3), enzimas hepáticas alteradas (GPT 70 U/L, GOT 45 U/L), proteína C Reactiva (96,3 mg/L) y RK39 negativo. Ecografía Abdominal: hepatomegalia y esplenomegalia. Tabla 1.

Frotis de Sangre Periférica: estructuras intracitoplasmáticas y extracelulares ovoides de 2-3 mm con núcleo excéntrico, presencia de kinetoplasto y citoplasma claro compatibles con Amastigotes de Leishmania spp. Fig. 1.

\section{DISCUSIÓN Y CONCLUSIONES}

Este es el primer reporte de diagnóstico de Leishmaniosis por frotis de sangre periférica en Asunción, Paraguay.

Lo que refiere a la prueba de inmunocromatografía para LVA con antígeno RK39 es empleada para detectar anticuerpos específicos en contra de los parásitos del género Leishmania pertenecientes al “complejo L. donovani” (L. donovani, L chagasi y L. infantum en las Américas) (L. chagasi y L. 
infantum son genéticamente similares), agentes de leishmaniasis visceral. Se utilizan tiras reactivas de nitrocelulosa, en las cuales se encuentra el antígeno RK39 y que por un sistema de migración cromatográfica son revelados los anticuerpos específicos en contra de dicho antígeno. La sensibilidad del método, es de $94,2 \%$ y la especificidad de la prueba es de $98 \%$ y no da reacciones cruzadas con el suero de personas con la enfermedad de Chagas ni con LTA. No obstante, la prueba solamente mide anticuerpos específicos en contra del antígeno RK39 (Alvar, 1977)

Es importante destacar que se produce una disminución en la sensibilidad del test en parasitemias bajas, generando resultados falsos negativos (Mars et al 2005).

Aunque la determinación de parásitos por sangre periférica no es un procedimiento de rutina, éste método permitió dimensionar la preocupante situación del ciclo de transmisión, pues el hombre en fase aguda podría convertirse en fuente natural de parásitos para el vector.

\section{AGRADECIMIENTOS}

Al Centro de Especialidades Dermatológicas (San Lorenzo, Paraguay) por el apoyo y a la Clínica Veterinaria Panda (Asunción, Paraguay) por la confianza. 


\section{REFERENCIAS BIBLIOGRÁFICAS}

1. Alvar Ezquerra J. La Leishmaniasis: de la Biología al Control. Laboratorio de Referencia para la Leishmaniasis. OMS. Servicio de Parasitología. Centro Nacional de Microbiología. Instituto de Salud Carlos III. España. 1997

2. A. Marx, D. Pewsner, M. Egger, R. Nuesch, H.C. Bucher, B. Genton, et al. Meta-analysis: accuracy of rapid tests for malaria in travelers returning from endemic areas. Ann Intern Med, 142 (2005), pp. 836-846

3. Ministerio de Salud Pública y Bienestar Social (MSPBS). Manual de Diagnóstico y Tratamiento de las Leishmaniasis. -- Asunción: OPS/OMS. - 2018. ISBN: 978-99967-36-74-2

4. Organización Panamericana de la Salud; 2019. Disponible en: www.paho.org/leishmaniasis

\section{ANEXO}

Tabla 1. Valores hematológicos.

\begin{tabular}{|l|l|l|}
\hline Valores & Resultados & Rango de Referencias \\
\hline Leucocitos & $3490 / \mathrm{mm} 3$ & $5000-10000 / \mathrm{mm} 3$ \\
\hline Neutrófilos segmentados & $74 \%$ & $55-65 \%$ \\
\hline Linfocitos & $12 \%$ & $23-35 \%$ \\
\hline Monocitos & $13 \%$ & $4-8 \%$ \\
\hline Eosinófilos & $0 \%$ & $0-4 \%$ \\
\hline Basófilos & $1 \%$ & $0-2 \%$ \\
\hline Eritrocitos & $5610000 / \mathrm{mm} 3$ & $4500000-5500000 / \mathrm{mm} 3$ \\
\hline Hemoglobina & $15.4 \mathrm{~g} / \mathrm{Dl}$ & $13-18 \mathrm{~g} / \mathrm{Dl}$ \\
\hline Hematocrito & $45.2 \%$ & $45-52 \%$ \\
\hline VCM & $80.6 \mathrm{Fl}$ & $86-98 \mathrm{FI}$ \\
\hline HCM & $27.5 \mathrm{pg}$ & $33-37 \mathrm{pg}$ \\
\hline Eritrosedimentación $\mathbf{1}^{\circ} \mathrm{Hora}$ & $12 \mathrm{~mm}$ & $1-13 \mathrm{~mm}$ \\
\hline Plaquetas & $154000 / \mathrm{mm} 3$ & $150000-450000 / \mathrm{mm} 3$ \\
\hline Urea & $22 \mathrm{mg} / \mathrm{dl}$ & $10-50 \mathrm{mg} / \mathrm{dl}$ \\
\hline Creatinina & $0.9 \mathrm{mg} / \mathrm{dl}$ & $0.7-1.4 \mathrm{mg} / \mathrm{dl}$ \\
\hline GPT & $70 \mathrm{U} / \mathrm{L}$ & $5-41 \mathrm{U} / \mathrm{L}$ \\
\hline GOT & $45 \mathrm{U} / \mathrm{L}$ & $5-40 \mathrm{U} / \mathrm{L}$ \\
\hline Fosfatasa Alcalina & $68 \mathrm{U} / \mathrm{L}$ & $40-129 \mathrm{U} / \mathrm{L}$ \\
\hline Bilirrubina Total & $0.41 \mathrm{mg} / \mathrm{dl}$ & Inferior a $1.20 \mathrm{mg} / \mathrm{dl}$ \\
\hline Bilirrubina Directa & $0.16 \mathrm{mg} / \mathrm{dl}$ & Inferior a $0.20 \mathrm{mg} / \mathrm{dl}$ \\
\hline Bilirrubina Indirecta & $0.25 \mathrm{mg} / \mathrm{dl}$ & Inferior a $1.00 \mathrm{mg} / \mathrm{dl}$ \\
\hline Proteína C Reactiva & $96.3 \mathrm{mg} / \mathrm{L}$ & Inferior a 5.0 mg/L \\
\hline
\end{tabular}




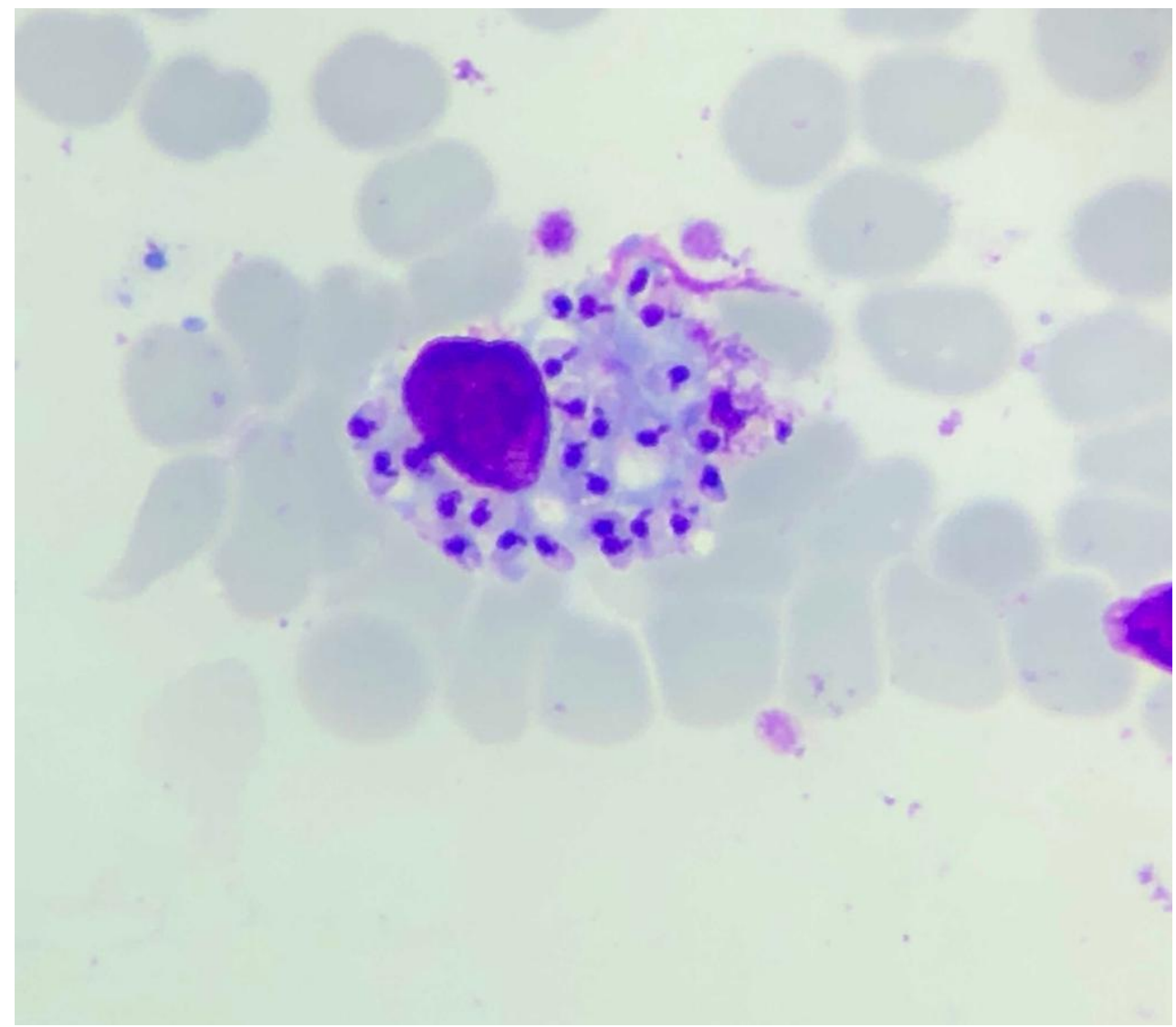

Fig.1 Frotis de sangre periférica macrófago con Amastigotes de Leishmania spp. Giemsa 100X 